CLINICAL STUDY

\title{
Methylenetetrahydrofolate reductase C677T polymorphism is associated with central adiposity and increased androgenicity in healthy postmenopausal women
}

\author{
Irene Lambrinoudaki, George Kaparos ${ }^{1}$, Dimitra Papadimitriou, Theodoros N Sergentanis, Maria Creatsa, \\ Andreas Alexandrou ${ }^{2}$, Emmanuel Logothetis ${ }^{1}$, George Christodoulakos and E Kouskouni ${ }^{1}$ \\ Second Department of Obstetrics and Gynecology, Aretaieio Hospital, University of Athens, 27, Themistokleous Street, Dionysos, GR-14578 Athens, \\ Greece, ${ }^{1}$ Hormonal and Biochemical Laboratory, Aretaieio Hospital, University of Athens, Athens, Greece and ${ }^{2}$ First Department of Surgery, University \\ of Athens Medical School, Laiko Hospital, Athens, Greece \\ (Correspondence should be addressed to I Lambrinoudaki; Email: ilambrinoudaki@hotmail.com)
}

\begin{abstract}
Objective: To assess the association of genetic polymorphisms related to cardiovascular disease (CVD) risk with anthropometric parameters and indices of androgenicity in healthy postmenopausal women. Design: Cross-sectional study in a University Menopause Clinic.

Methods: The following polymorphisms were assessed in 84 healthy postmenopausal women: glycoprotein IIIa Leu33Pro, apolipoprotein E2/E3/E4, methylenetetrahydrofolate reductase (MTHFR) Ala222Val, apolipoprotein B Arg3500Gln, paraoxonase $1 \mathrm{Gln} 192 \mathrm{Arg}$, plasminogen activator inhibitor 1 4G/5G, cholesterol-7 $\alpha$-hydroxylase A-204C, and cholesterol ester transfer protein (TaqIB) B1/B2. Hormonal assays included FSH, LH, 17- $\beta$-estradiol, testosterone, sex hormone-binding globulin (SHBG), DHEA sulfate, $\Delta$-4-androstenedione $(\Delta 4 \mathrm{~A})$, free androgen index (FAI), free estrogen index (FEI), and homocysteine (Hcy). The anthropometric components were body mass index (BMI) and waist-to-hip ratio (WHR).

Results: MTHFR Ala222Val polymorphism was positively associated with testosterone, FAI, and FEI ( $P=0.001, P=0.0004$, and $P=0.014$ respectively) and negatively with SHBG $(P=0.047)$. Furthermore, women bearing this polymorphism had higher BMI and WHR compared with women with the wild-type variant ( $P=0.027$ and $P=0.044$ respectively).

Conclusions: MTHFR Ala222Val polymorphism is associated with increased androgenicity and elevated BMI and WHR in healthy postmenopausal women. The significance of this association with respect to the CVD risk of postmenopausal women remains to be elucidated in future studies.
\end{abstract}

European Journal of Endocrinology 159 233-241

\section{Introduction}

Menopause-associated estrogen deficiency has metabolic and vascular consequences that increase the risk for cardiovascular disease (CVD). The increased prevalence of CVD after menopause has been partially attributed to the adverse effects of estrogen deficiency on plasma lipidlipoprotein levels. Menopause associates with an atherogenic profile: increased levels of total and low density lipoprotein (LDL) cholesterol, triglycerides, and Lp(a), and decreased levels of high-density lipoprotein (HDL) cholesterol (1). Of particular importance for the menopausal women are the increased levels of triglycerides, for they associate with the presence of small dense and very lowdensity particles (1). Furthermore, menopause is related to small increases of both systolic and diastolic blood pressure and increased sympathetic tone. Among the vascular consequences, endothelial dysfunction and vascular inflammation are reported to be augmented (2).
Postmenopause is associated with significant changes in obesity indices. Waist-to-hip ratio (WHR), reflecting abdominal adiposity, increases significantly after menopausal transition (3). High body mass index (BMI) and WHR have been correlated with increased risk for CVD, diabetes mellitus type 2 , and other aspects of the metabolic syndrome $(4,5)$. Furthermore, menopause is associated with reduced glucose tolerance (1). Diet changes, excess weight, central obesity, and sedentary way of life, frequently associating with advancing age, concur to alter glucose tolerance and increase insulin resistance. Impaired glucose tolerance and diabetes mellitus may be found in nearly 20\% of women aged 55-65 years. Additionally, estrogen deficiency may lead to decreased pancreatic insulin secretion (2).

High androgenicity in women may be a signal of increased risk for coronary artery disease (6). Elevated androgen levels have been associated with central obesity, insulin resistance, and the development of 
type 2 diabetes mellitus $(7,8)$. Regarding postmenopausal women, data suggest that androgenicity may contribute to the development of insulin resistance independently of obesity (7).

Beyond metabolic factors, the genetic background may affect the risk of CVD in postmenopausal women. Polymorphisms in genes involved in homocysteine (Hcy) and lipid metabolism, oxidative stress as well as the hemostasis cascade have been reported to influence the susceptibility to ischemic heart disease, stroke, and venous thromboembolism in men. However, the relevant data for postmenopausal women are sparse. Glycoprotein IIIa Leu 33Pro polymorphism is correlated with a sixfold increase in the risk of myocardial infarction in homozygous carriers of the unfavorable PLA2 (pro/pro) allele, compared with PLA1 homo- or heterozygotes (9). Apolipoprotein E2/E3/E4 polymorphism is associated with increased blood cholesterol concentrations as well as with increased risk of myocardial infarction (10). Methylenetetrahydrofolate reductase (MTHFR) Ala222Val polymorphism may lead to elevated Hcy levels that are associated with increased risk of thromboembolism, atherosclerosis, and myocardial infarction (11). Apolipoprotein B Arg3500Gln polymorphism is associated with increased LDL cholesterol and elevated risk of ischemic heart disease (12). Paraoxonase 1 Gln192Arg polymorphism is related to augmented exposure of HDL to oxidation (13). Plasminogen activator inhibitor $14 \mathrm{G}$ / $5 \mathrm{G}$ polymorphism is responsible for increased levels of plasminogen activator inhibitor (PAI)-1, leading to an elevated risk for obesity (BMI), hypertension, dyslipidemia, insulin resistance, metabolic syndrome, and type 2 diabetes mellitus (14). Cholesterol-7 $\alpha$-hydroxylase A-204C polymorphism increases the expression of circulating cholesterol levels (15). Finally, cholesterol ester transfer protein (TaqIB) B1/B2 polymorphism is correlated with reduced levels of HDL cholesterol and increased risk of myocardial infarction in men (16). In order to globally assess the diptych CVD-androgenicity, the whole spectrum of the aforementioned polymorphisms has been included in this study.

The preventive management of the postmenopausal women with respect to their personal CVD risk bears a high significance in clinical practice. Given the paucity of data in postmenopausal women, the present study aimed to investigate the association of genetic polymorphisms known to affect CVD risk in men with anthropometric and hormonal factors in healthy postmenopausal women.

\section{Subjects and methods}

\section{Subjects}

Subjects were recruited from the Menopause Clinic of the Second Department of Obstetrics and Gynecology, University of Athens, Aretaieion Hospital. They consisted of 84 women aged 49-69 years who had been menopausal for at least 1 year. Women who were past users of HT, tibolone, or raloxifene were not included in the study unless they had been off-therapy for at least 6 months.

Before recruitment, patients had a gynecological and biochemical evaluation that included: bimanual examination, Papanicolaou (Pap) smear and transvaginal sonography, breast examination and mammography, thyroid-liver-renal function, as well as blood coagulation tests and bone densitometry. Criteria for inclusion were the absence of climacteric complaints, an endometrial thickness $<5 \mathrm{~mm}$, the absence of a history of gynecological malignancy, ischemic heart disease, thromboembolism, diabetes mellitus, nontreated thyroid dysfunction, and the intake of lipidlowering or antihypertensive medication. Patients were instructed to fast and not to smoke for $12 \mathrm{~h}$ before blood collection. Samples were centrifuged immediately and stored at $-80{ }^{\circ} \mathrm{C}$, until assayed.

Anthropometric components were assessed in the morning in light clothing, in order to estimate BMI and WHR. Height was measured by using a stadiometer in the upright position and weight was measured on an electronic scale. BMI was calculated using the following equation: $\mathrm{BMI}=$ body weight $(\mathrm{kg}) /$ height $^{2}(\mathrm{~m})$. Waist circumference was measured at the midpoint between the bottom of the rib cage and the top of the lateral border of the iliac crest during minimal respiration. Hip circumference was measured approximately $10 \mathrm{~cm}$ below the lateral border of the iliac crest. WHR was estimated using the values resulting from the above measurements. Written informed consent was obtained by all participants. The local Institutional Review Board has approved the present study.

\section{Hormonal assays}

Follicle-stimulating hormone (FSH) and luteinizing hormone were measured with the Microparticle Enzyme Immunoassay kit: Abbott Axsym measured on the AxsymR analyzer (Abbott Laboratories). The total coefficient of variation $(\mathrm{CV})$ ranged from 5.3 to $8.5 \%$. 17- $\beta$-Estradiol $\left(\mathrm{E}_{2}\right)$ was measured with a commercial enzyme immunoassay kit: DSK-10-4300 (Diagnostic Systems Laboratories Inc., Webster, TX, USA). The total CV ranged from 4.3 to $6.1 \%$ and the analytical sensitivity was $8 \mathrm{pg} / \mathrm{ml} . \Delta$-4-Androstenedione $(\Delta 4 \mathrm{~A})$ was measured with an IBL Androstenedione ELISA' kit (IBL GmbH, Hamburg, Germany). The inter-assay $\mathrm{CV}$ ranged from 6.5 to $8.1 \%$. Total testosterone and DHEA-SO $\mathrm{S}_{4}$ were measured with DPC 'Total Testosterone' and 'DHEA-SO4' Immulite analyzer kits (Diagnostic Products Corporation, Los Angeles, CA, USA). The total CV ranged from 8.0 to $16.0 \%$ and from 8.1 to $15 \%$ respectively. Sex hormone-binding globulin (SHBG) concentrations were measured with a DPC Immulite SHBG chemiluminescent enzyme 
immunometric assay kit (Diagnostic Products Corporation). The total CV ranged from 4.1 to $9.2 \%$. The free estrogen index (FEI) was calculated using total $\mathrm{E}_{2}$ and SHBG values by the following equation: $\mathrm{FEI}=\mathrm{E}_{2}$ $(\mathrm{pg} / \mathrm{ml}) \times 0.367 / \mathrm{SHBG}(\mathrm{nmol} / \mathrm{l})$. The free androgen index (FAI) was calculated using total testosterone and SHBG values by the following equation: $\mathrm{FAI}=$ testosterone $(\mathrm{ng} / \mathrm{ml}) \times 3.47 \times 100 /$ SHBG $(\mathrm{nmol} / \mathrm{l})$. Fasting blood samples were also used to assess Hcy levels. Total Hcy concentrations were measured by the Abbott commercial kit: IMx Hcy (Abbott Lab). The total CV $(\%)$ and the sensitivity was $4.3 \%$ and $0.5 \mu \mathrm{mol} / \mathrm{l}$ respectively.

\section{Gene polymorphism assays}

Isolation of genomic DNA was made from $200 \mu \mathrm{l}$ whole blood treated with EDTA by using the blood spin protocol of QIAamp DNA Blood Mini Kit from Qiagen Corporation. Measurement of polymorphisms was made after Multiplex-PCR and Array Tube ${ }^{\mathrm{R}}$ hybridization using the coro/check protocol for solas 2 (Ogham Diagnostics GmbH, Münster, Germany). The following polymorphisms were assessed: glycoprotein IIIa Leu33Pro, apolipoprotein E2/E3/E4, MTHFR Ala222Val, apolipoprotein B Arg3500Gln, paraoxonase 1 Gln192Arg, plasminogen activator inhibitor 1 4G/5G, cholesterol-7 $\alpha$-hydroxylase A-204C, and cholesterol ester transfer protein (TaqIB) B1/B2 polymorphism.

\section{Statistical analysis}

Statistical analysis was performed with STATA 8.0 statistical software (Stata Corporation, College Station, TX, USA). Polymorphisms have been treated as ordinal, 0-1-2 variables (0, wild-type; 1 , heterozygous; 2 , homozygous). At the univariate approach, the associations between polymorphisms and hormone variables were evaluated by means of Spearman's rank correlation coefficient.

Subsequently, concerning MTHFR polymorphism, to adjust the univariate $P$ for BMI, ordinal logistic regression was performed for all hormone variables in Tables 2 and 3 having exhibited a statistically significant association (except for FEI). More specifically, using the first, second, and third quartiles, a four-level variable was created for each hormone. The four-level variable was treated as the dependent variable in the ordinal logistic model, whereas BMI and MTHFR polymorphism status were included as independent variables (covariates). Regarding the effect of the MTHFR polymorphism status, a linear effect was assumed in the log-odds scale; thus, no dummy variables were created and the polymorphism status was again treated as a $0-1-2$ variable. Concerning all models, the proportionality-of-odds assumption was checked by the appropriate likelihood ratio test.
The proportionality-of-odds assumption was valid for all hormone parameters examined, except for FEI. For the latter, linear regression was performed, with BMI and MTHFR status entered as covariates. The normality assumption was verified using the Shapiro-Wilk criterion upon the studentized (jackknifed) residuals.

\section{Results}

Table 1 presents the baseline demographic characteristics of the 84 postmenopausal women under investigation. Women were on average 8 years postmenopausal, slightly overweight, and normotensive while $30 \%$ of them were smokers.

Tables 2 and 3 present the association of the genetic polymorphisms studied with the hormonal profile of the participants. There is a statistically significant association between MTHFR polymorphism and levels of testosterone, SHBG, FAI, and FEI in postmenopausal women $(P=0.001, P=0.047, P=0.0004$, and $P=0.014$ respectively) and a trend toward a positive correlation with DHEA sulfate (DHEAS) and $\Delta 4 \mathrm{~A}$ $(P=0.053$ and $P=0.054$ respectively). On the other hand, an inverse correlation has been observed between SHBG and the presence of MTHFR polymorphisms $(P=0.047)$. These associations were independent of smoking status or lipid levels across groups. The association of MTHFR polymorphism with testosterone and FAI persisted after adjustment for BMI $(P=0.007$ and $P=0.005$ respectively). Furthermore, the E2/E3 and E3/E4 genotypes of the apolipoprotein E polymorphism associated with testosterone $(P=0.023)$. Finally, there was a statistically significant positive association between glycoprotein IIIa Leu33Pro polymorphism and FSH levels $(P=0.01)$.

Table 4 presents the association of the genetic polymorphisms studied with Hcy plasma concentrations (Hcy), BMI, and WHR. MTHFR Ala222Val polymorphism bears a statistically significant association with BMI and WHR $(P=0.027$ and $P=0.044$ respectively). Heterozygosity and homozygosity for this polymorphism were both related to higher mean BMI (28.6 \pm 5.3 and $26.7 \pm 2.6$ respectively) compared with

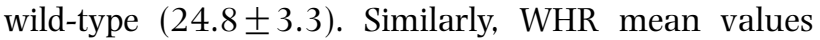
were higher in heterozygous and homozygous carriers $(0.88 \pm 0.05$ and $0.91 \pm 0.05$ respectively) compared with wild-type $(0.85 \pm 0.08)$. Smoking and lipid levels did not affect this association.

\section{Discussion}

The present study demonstrates an association of MTHFR Ala222Val polymorphism with central adiposity and indices of androgenicity in healthy postmenopausal women. More specifically, the presence of the MTHFR polymorphism was associated with 
Table 1 Study group characteristics.

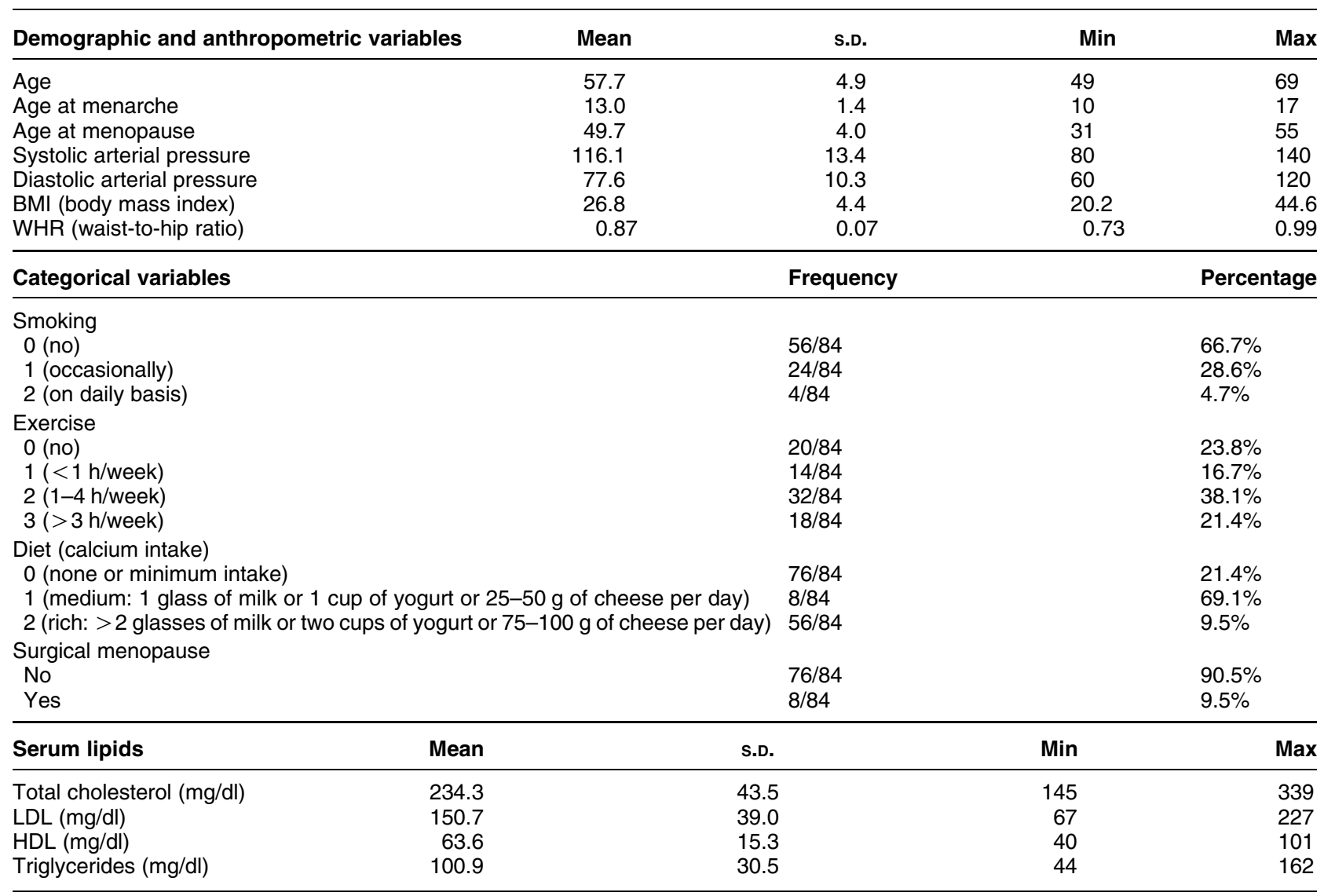

higher BMI, WHR, and serum androgens and with lower SHBG. On the contrary, apolipoprotein E2/E3 and E3/E4 polymorphisms are associated with suppressed testosterone levels, acting inversely compared with MTHFR polymorphism.

Hcy is a thiamine acid metabolized via two major pathways. When there is an excess of methionine, Hcy converts, through the trans-sulfuration pathway that requires vitamin $\mathrm{B}_{6}$ as a co-factor, into cystathionine, and is finally metabolized to cysteine. By contrast, when methionine levels are low, Hcy is metabolized to methionine, through remethylation, a process that is catalyzed by the enzyme MTHFR. The Ala222Val (C677T) polymorphism in the MTHFR gene is characterized by a substitution of alanine for valine leading to the formation of a thermolabile enzyme that maintains only $50 \%$ of the normal activity. The wild-type genotype (Ala/Ala) exists in $75 \%$, while heterozygosity (Ala/Val) exists only in $10 \%$ of the general population. Homozygosity for the valine variant (Val/Val) is present in about $15 \%$ of the general population (Fig. 1).

The Ala222Val polymorphism in the MTHFR gene has been associated with increased risk of ischemic heart disease, stroke, and venous thromboembolism $(11,19,20)$. An increase in serum Hcy has been suggested as a possible mechanism (21). In contrast to this hypothesis, data indicate that lowering of Hcy levels by vitamin $\mathrm{B}$ and folate supplementation has not resulted in CVD risk reduction (22). Furthermore, Ala222Val polymorphism, although reported to increase CVD risk, may not be associated with hyperhomocysteinemia (18).

Insulin resistance has been proposed as a possible mechanism linking defects in Hcy catabolism and CVD risk. Polycystic ovary syndrome (PCOS), characterized by central adiposity, increased androgenicity, and insulin resistance, has been associated with defects in Hcy metabolism. Carlsen et al. (23) reported a positive association between Hcy levels and free testosterone index, as well as $\Delta 4$ levels in PCOS women. This association persisted after adjustment for fasting plasma insulin C-peptide. According to the above, there is an independent positive association between androgens and Hcy metabolism, which may be independent of glucose disposal.

Further to the association with androgens, many studies have demonstrated an association of Hcy metabolism with insulin resistance. Insulin levels are associated with increased plasma levels of Hcy in healthy, non-obese subjects (24). Several studies support the hypothesis that insulin resistance is the determinant of Hcy metabolic defect in PCOS women. 
Table 2 Association between genetic polymorphisms and follicle-stimulating hormone (FSH), luteinizing hormone (LH), 17- $\beta$-estradiol ( $\left.E_{2}\right)$, and free estrogen index (FEI).

\begin{tabular}{|c|c|c|c|c|c|c|c|c|}
\hline Polymorphisms & $\begin{array}{l}\text { FSH }(\mathrm{mlU} / \mathrm{ml}) \\
\text { mean (s.D.) }\end{array}$ & $P$ & $\begin{array}{l}\mathrm{LH}(\mathrm{mlU} / \mathrm{ml}) \\
\text { mean (s.D.) }\end{array}$ & $P$ & $\begin{array}{l}E_{2}(p g / m l) \\
\text { mean (s.D.) }\end{array}$ & $P$ & $\begin{array}{l}\text { FEI } \\
\text { mean (s.D.) }\end{array}$ & $\boldsymbol{P}$ \\
\hline Methylenetetrahydrofolate reductase & & 0.936 & & 0.376 & & 0.773 & & 0.014 \\
\hline Ala222Val & & & & & & & & \\
\hline Wild-type & $88.4(43.4)$ & & $46.1(15.5)$ & & $28.4(8.5)$ & & $0.15(0.04)$ & \\
\hline Heterozygous & $68.5(17.3)$ & & $35.6(13.4)$ & & $22.8(4.5)$ & & $0.18(0.10)$ & \\
\hline Homozygous & $89.9(30.2)$ & & $44.4(10.4)$ & & $36.3(16.5)$ & & $0.27(0.07)$ & \\
\hline Glycoprotein IIla Leu33Pro & & 0.010 & & 0.614 & & 0.203 & & 0.920 \\
\hline Wild-type & $86.1(33.6)$ & & $42.4(15.2)$ & & $27.8(10.1)$ & & $0.18(0.08)$ & \\
\hline Heterozygous & $56.2(16.8)$ & & $36.3(11.8)$ & & $25.4(10.6)$ & & $0.19(0.12)$ & \\
\hline Apolipoprotein E2/E3/E4 & & 0.879 & & 0.633 & & 0.863 & & 0.497 \\
\hline E3/E3 & $81.2(32.5)$ & & $43.0(15.4)$ & & $27.4(10.7)$ & & $0.19(0.10)$ & \\
\hline E3/E2 & $76.8(56.6)$ & & $31.4(18.2)$ & & $24.3(9.3)$ & & $0.17(0.03)$ & \\
\hline E3/E4 & $82.2(23.2)$ & & $40.1(5.6)$ & & $26.2(7.8)$ & & $0.15(0.08)$ & \\
\hline Apolipoprotein B Arg3500GIn & & 0.542 & & 0.113 & & 0.344 & & 0.231 \\
\hline Wild-type & $79.6(33.5)$ & & $40.3(14.2)$ & & $27.4(10.0)$ & & $0.18(0.09)$ & \\
\hline Heterozygous & $82.8(15.0)$ & & $55.3(14.4)$ & & $20.0(15.0)$ & & $0.10(0.14)$ & \\
\hline Paraoxonase 1 Gln192Arg & & 0.875 & & 0.914 & & 0.431 & & 0.548 \\
\hline Wild-type & $76.3(27.2)$ & & $39.3(12.6)$ & & $28.2(9.8)$ & & $0.18(0.09)$ & \\
\hline Heterozygous & $81.9(28.6)$ & & $45.9(14.9)$ & & $26.9(11.0)$ & & $0.17(0.07)$ & \\
\hline Homozygous & $85.5(67.1)$ & & $29.7(14.3)$ & & $24.5(7.6)$ & & $0.24(0.11)$ & \\
\hline Plasminogen activator inhibitor $14 \mathrm{G} / 5 \mathrm{G}$ & & 0.297 & & 0.097 & & 0.776 & & 0.930 \\
\hline Wild-type & $92.1(43.4)$ & & $40.9(6.5)$ & & $23.1(4.4)$ & & $0.12(0.06)$ & \\
\hline Heterozygous & $85.5(34.2)$ & & $47.0(18.4)$ & & $28.6(12.2)$ & & $0.20(0.06)$ & \\
\hline Homozygous & $70.0(23.4)$ & & $35.9(11.4)$ & & $26.3(7.6)$ & & $0.18(0.11)$ & \\
\hline Cholesterol-7 $\alpha$-hydroxylase A-204C & & 0.911 & & 0.770 & & 0.146 & & 0.244 \\
\hline Wild-type & $77.4(30.5)$ & & $42.3(17.2)$ & & $29.8(13.2)$ & & $0.16(0.08)$ & \\
\hline Heterozygous & $84.8(40.0)$ & & $40.7(12.1)$ & & $27.1(8.4)$ & & $0.19(0.09)$ & \\
\hline Homozygous & $72.1(9.5)$ & & $40.4(16.6)$ & & $22.3(3.8)$ & & $0.20(0.09)$ & \\
\hline Cholesterol ester transfer protein B1/B2 & & 0.880 & & 0.890 & & 0.356 & & 0.236 \\
\hline Homozygous & $85.6(36.0)$ & & $42.5(20.0)$ & & $26.1(6.8)$ & & $0.16(0.03)$ & \\
\hline Heterozygous & $73.0(24.7)$ & & $41.9(14.4)$ & & $24.1(7.1)$ & & $0.16(0.08)$ & \\
\hline Wild-type & $77.9(25.2)$ & & $38.3(9.7)$ & & $31.7(13.6)$ & & $0.23(0.12)$ & \\
\hline
\end{tabular}

Bold indicates statistically significant $(P<0.05)$ associations between the examined variants. Bold and italics indicates the presence of weaker correlations $(0.05<P<0.1)$ between the variants. 
Table 3 Association between genetic polymorphisms and male sex hormones: testosterone (Testo), sex hormone-binding globulin (SHBG), DHEA sulfate (DHEAS), $\Delta-4-$ androstenedione $(\triangle 4 \mathrm{~A})$, and free androgen index $(\mathrm{FAl})$.

\begin{tabular}{|c|c|c|c|c|c|c|c|c|c|c|}
\hline Polymorphisms & $\begin{array}{l}\text { Testosterone }(\mathrm{ng} / \mathrm{ml}) \\
\text { mean (S.D.) }\end{array}$ & $\boldsymbol{P}$ & $\begin{array}{l}\text { SHBG }(\mathrm{nmol} / \mathrm{l}) \\
\text { mean (S.D.) }\end{array}$ & $\boldsymbol{P}$ & $\begin{array}{l}\text { DHEAS } \\
\text { (ng/dl) mean } \\
\text { (S.D.) }\end{array}$ & $\boldsymbol{P}$ & $\begin{array}{l}\Delta 4 A(n g / d l) \\
\text { mean (s.D.) }\end{array}$ & $\boldsymbol{P}$ & $\begin{array}{l}\text { FAI mean } \\
\text { (S.D.) }\end{array}$ & $P$ \\
\hline Methylenetetrahydrofolate reductase & & 0.001 & & 0.047 & & 0.053 & & 0.054 & & 0.0004 \\
\hline Ala222Val & & & & & & & & & & \\
\hline Wild-type & $0.23(0.13)$ & & 75.9 (27.3) & & $598.9(272.0)$ & & $129.8(63.2)$ & & $1.06(0.56)$ & \\
\hline Heterozygous & $0.37(0.12)$ & & $60.8(41.0)$ & & $833.3(527.2)$ & & $175.6(69.7)$ & & $2.93(1.97)$ & \\
\hline Homozygous & $0.42(0.15)$ & & $60.1(4.2)$ & & $963.4(358.5)$ & & $224.8(130.3)$ & & $2.36(0.89)$ & \\
\hline Glycoprotein IIla Leu33Pro & & 0.119 & & 0.461 & & 0.870 & & 0.497 & & 0.175 \\
\hline Wild-type & $0.30(0.15)$ & & $68.7(35.0)$ & & $778.2(473.9)$ & & $162.3(86.5)$ & & $1.89(1.41)$ & \\
\hline Heterozygous & $0.38(0.13)$ & & $57.8(29.2)$ & & $735.3(316.1)$ & & $179.1(73.7)$ & & $2.97(2.29)$ & \\
\hline Apolipoprotein E2/E3/E4 & & 0.023 & & 0.752 & & 0.149 & & 0.236 & & 0.079 \\
\hline E3/E3 & $0.36(0.13)$ & & $61.2(25.4)$ & & $838.3(489.0)$ & & $180.7(86.3)$ & & $2.55(1.82)$ & \\
\hline E3/E2 & $0.17(0.14)$ & & $54.7(30.7)$ & & $590.3(272.3)$ & & $130.0(77.3)$ & & $1.15(0.98)$ & \\
\hline E3/E4 & $0.26(0.14)$ & & $79.1(50.5)$ & & $562.3(204.7)$ & & $136.5(74.3)$ & & $1.41(0.78)$ & \\
\hline Apolipoprotein B Arg3500GIn & & 0.517 & & 0.218 & & 0.178 & & 0.506 & & 0.304 \\
\hline Wild-type & $0.33(0.15)$ & & $65.2(34.5)$ & & $789.3(441.9)$ & & $168.6(85.0)$ & & $2.20(1.70)$ & \\
\hline Heterozygous & $0.26(0.11)$ & & $83.0(12.9)$ & & $435.0(70.7)$ & & $131.5(0.7)$ & & $1.14(0.65)$ & \\
\hline Paraoxonase 1 Gln192Arg & & 0.589 & & 0.167 & & 0.953 & & 0.579 & & 0.878 \\
\hline Wild-type & $0.34(0.12)$ & & $74.5(41.3)$ & & $827.3(511.1)$ & & $178.7(77.2)$ & & $2.21(1.79)$ & \\
\hline Heterozygous & $0.31(0.18)$ & & $64.0(21.0)$ & & $638.2(352.0)$ & & $146.3(95.1)$ & & $1.60(1.12)$ & \\
\hline Homozygous & $0.31(0.09)$ & & $43.3(31.2)$ & & $998.0(332.4)$ & & $190.3(51.4)$ & & $3.41(2.25)$ & \\
\hline Plasminogen activator inhibitor & & 0.204 & & 0.835 & & 0.370 & & 0.138 & & 0.465 \\
\hline Wild-type & $0.31(0.13)$ & & $80.0(53.0)$ & & $610.2(306.7)$ & & $120.8(54.8)$ & & $1.91(1.38)$ & \\
\hline Heterozygous & $0.27(0.16)$ & & $53.9(18.1)$ & & $818.4(572.5)$ & & $155.3(73.4)$ & & $1.73(1.19)$ & \\
\hline Homozygous & $0.36(0.13)$ & & $68.4(33.3)$ & & $773.2(369.5)$ & & $186.2(91.7)$ & & $2.52(2.10)$ & \\
\hline Cholesterol-7 $\alpha$-hydroxylase A-204C & & 0.766 & & 0.119 & & 0.828 & & 0.660 & & 0.299 \\
\hline Wild-type & $0.34(0.18)$ & & $82.2(43.0)$ & & $875.9(578.2)$ & & $171.7(81.1)$ & & $1.79(1.23)$ & \\
\hline Heterozygous & $0.31(0.14)$ & & $59.9(25.1)$ & & $677.1(333.6)$ & & $168.4(97.6)$ & & $2.12(1.88)$ & \\
\hline Homozygous & $0.34(0.09)$ & & $54.3(26.5)$ & & 792.1 (396.3) & & $153.6(55.5)$ & & $2.78(1.92)$ & \\
\hline $\begin{array}{l}\text { Cholesterol ester transfer protein } \\
\text { B1/B2 }\end{array}$ & & 0.112 & & 0.563 & & 0.258 & & 0.959 & & 0.181 \\
\hline Homozygous & $0.23(0.11)$ & & $65.5(25.0)$ & & $855.1(652.1)$ & & $155.1(83.0)$ & & $1.42(1.14)$ & \\
\hline Heterozygous & $0.34(0.12)$ & & $67.2(39.3)$ & & $812.1(333.5)$ & & $172.0(84.7)$ & & $2.30(1.54)$ & \\
\hline Wild-type & $0.36(0.18)$ & & $62.5(34.7)$ & & $559.1(367.6)$ & & $150.4(78.9)$ & & $2.60(2.42)$ & \\
\hline
\end{tabular}

Bold indicates statistically significant $(P<0.05)$ associations between the examined variants. Bold and italics indicates the presence of weaker correlations $(0.05<P<0.1)$ between the variants. 
Table 4 Association between genetic polymorphisms and homocysteine plasma concentrations (Hcy), body mass index (BMI), and waistto-hip ratio (WHR).

\begin{tabular}{|c|c|c|c|c|c|c|}
\hline Polymorphisms & $\begin{array}{l}\text { Hcy }(\mathrm{mmol} / \mathrm{l}) \\
\text { mean (s.D.) }\end{array}$ & $\boldsymbol{P}$ & $\begin{array}{l}\text { BMI } \\
\text { mean (S.D.) }\end{array}$ & $\boldsymbol{P}$ & $\begin{array}{l}\text { WHR } \\
\text { mean (s.D.) }\end{array}$ & $\boldsymbol{P}$ \\
\hline $\begin{array}{l}\text { Methylenetetrahydrofolate reductase } \\
\text { Ala222Val }\end{array}$ & & 0.486 & & 0.027 & & 0.044 \\
\hline Wild-type & $14.0(8.0)$ & & $24.8(3.3)$ & & $0.85(0.08)$ & \\
\hline Heterozygous & $10.7(3.4)$ & & $28.6(5.3)$ & & $0.88(0.05)$ & \\
\hline Homozygous & $11.5(3.1)$ & & $26.7(2.6)$ & & $0.91(0.05)$ & \\
\hline Glycoprotein IIla Leu33Pro & & 0.758 & & 0.317 & & 0.145 \\
\hline Wild-type & $11.8(3.8)$ & & $26.1(3.6)$ & & $0.86(0.07)$ & \\
\hline Heterozygous & $13.6(9.9)$ & & $28.5(6.2)$ & & $0.90(0.05)$ & \\
\hline Apolipoprotein E2/E3/E4 & & 0.678 & & 0.430 & & 0.585 \\
\hline E3/E3 & $12.1(6.6)$ & & $27.4(4.6)$ & & $0.88(0.06)$ & \\
\hline E3/E2 & $13.8(4.6)$ & & $25.2(4.5)$ & & $0.83(0.04)$ & \\
\hline E3/E4 & $11.0(3.2)$ & & $25.9(3.4)$ & & $0.89(0.06)$ & \\
\hline Apolipoprotein B Arg3500GIn & & 0.249 & & 0.062 & & 0.033 \\
\hline Wild-type & $12.4(5.9)$ & & $27.0(4.4)$ & & $0.88(0.06)$ & \\
\hline Heterozygous & $8.5(0.1)$ & & $22.1(2.1)$ & & $0.79(0.01)$ & \\
\hline Paraoxonase 1 Gln192Arg & & 0.378 & & 0.209 & & 0.365 \\
\hline Wild-type & $13.7(7.6)$ & & $26.7(5.7)$ & & $0.88(0.06)$ & \\
\hline Heterozygous & $10.8(3.7)$ & & $26.6(3.5)$ & & $0.88(0.08)$ & \\
\hline Homozygous & $11.4(3.9)$ & & $27.4(2.8)$ & & $0.85(0.05)$ & \\
\hline Plasminogen activator inhibitor $14 \mathrm{G} / 5 \mathrm{G}$ & & 0.664 & & 0.928 & & 0.031 \\
\hline Wild-type & $11.1(4.1)$ & & $26.1(2.7)$ & & $0.91(0.07)$ & \\
\hline Heterozygous & $12.2(3.8)$ & & $26.9(4.0)$ & & $0.88(0.06)$ & \\
\hline Homozygous & $10.6(3.7)$ & & $27.2(5.7)$ & & $0.84(0.06)$ & \\
\hline Cholesterol-7 $\alpha$-hydroxylase A-204C & & 0.118 & & 0.485 & & 0.930 \\
\hline Wild-type & $14.2(8.6)$ & & $25.8(3.9)$ & & $0.86(0.07)$ & \\
\hline Heterozygous & $11.9(3.5)$ & & $27.1(4.7)$ & & $0.89(0.07)$ & \\
\hline Homozygous & $8.6(1.7)$ & & $27.4(4.7)$ & & $0.86(0.06)$ & \\
\hline Cholesterol ester transfer protein B1/B2 & & 0.250 & & 0.221 & & 0.945 \\
\hline Homozygous & $13.3(4.2)$ & & $24.6(3.2)$ & & $0.87(0.06)$ & \\
\hline Heterozygous & $10.4(3.4)$ & & $27.7(3.1)$ & & $0.89(0.06)$ & \\
\hline Wild-type & $10.9(3.4)$ & & $27.7(6.8)$ & & $0.87(0.09)$ & \\
\hline
\end{tabular}

Bold indicates statistically significant $(P<0.05)$ associations between the examined variants. Bold and italics indicates the presence of weaker correlations $(0.05<P<0.1)$ between the variants.

Guzelmeric et al. (17) reported a positive association of Hcy levels with BMI, total testosterone, free testosterone, insulin levels, and HOMA-IR in women with PCOS and that BMI is the main factor predicting Hcy levels. According to Bjork et al. (27), serum Hcy associated positively with serum insulin as well as with insulin resistance independently of age and sex. By contrast, Schachter et al. (26) suggested that insulin resistance and hyperinsulinemia in patients with PCOS is associated with elevated plasma Hcy, independently of body weight.

Several mechanisms may explain the association of Hcy metabolism with insulin resistance. Studies in cell cultures have indicated that elevated insulin levels affect the activity of enzymes participating in Hcy metabolism and this has been most consistently shown for cystathionine $\beta$-synthase, which converts Hcy to cysteine. MTHFR and methionine synthase activity were also influenced by insulin levels, although the evidence seems to be controversial. McCarty et al. (25) reported that the association between insulin resistance and hyperhomocysteinemia may reflect that hyperinsulinemia suppresses hepatocyte expression of cystathionine $\beta$-synthase, as demonstrated in rats. The above alterations caused by increased insulin levels, as in insulin resistance, lead to tissue Hcy accumulation. Defects in Hcy metabolism, through decreased glutathione levels and the generation of reactive oxygen species $(\mathrm{ONOO}-)$, may lead to endothelial damage that favors insulin resistance and elevated insulin levels $(28,29)$. According to the above hypothesis, Hcy

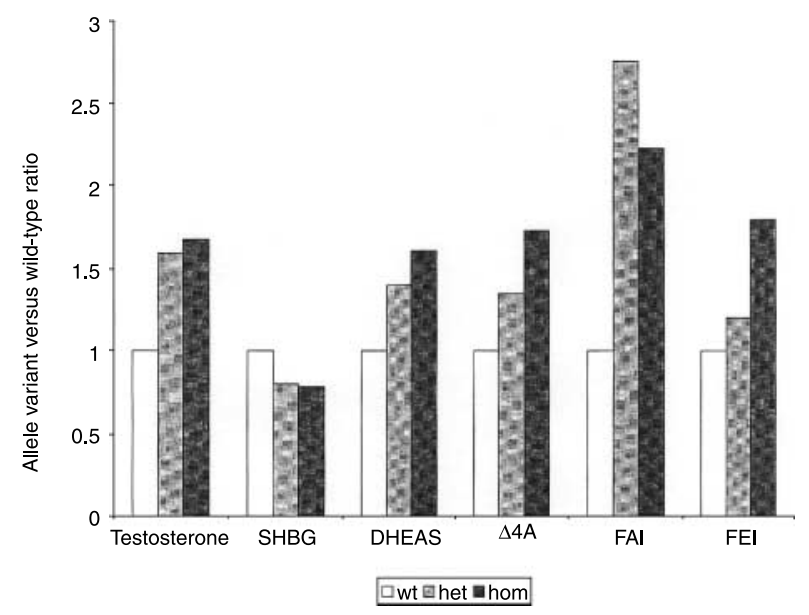

Figure 1 MTHFR allele variant to wild-type ratio of mean sex hormone levels. Wt, wild-type; het, heterozygous; hom, homozygous. 
metabolism and insulin resistance are related in terms of a vicious cycle and the atherogenic effects of Hcy may, in part, be manifested through insulin resistance.

In contrast to previous reports, the present study indicates that MTHFR Ala222Val polymorphism does not significantly increase Hcy levels. However, we observed a statistically significant association between MTHFR Ala222Val polymorphism and androgenicity, BMI, and WHR. Insulin resistance bears an independent positive association with total testosterone and FAI (30), while it correlates positively with indices of obesity such as BMI and WHR (31). We propose the following hypothesis: genetic defects in Hcy metabolism may result in impaired Hcy catabolism which, at a cellular level, may lead to endothelial dysfunction thus causing insulin resistance. This metabolic disturbance is related to increased androgenicity, BMI, and WHR.

Apolipoprotein E polymorphism and more specifically $\mathrm{E} 2 / \mathrm{E} 3$ and E3/E4 genotypes are associated in the present study with lower levels of testosterone. Apolipoprotein $\mathrm{E}$ is a peptide responsible for the transportation and redistribution of lipids, including cholesterol. Cholesterol acts as the main substrate for steroidogenesis in both adrenal and gonads. Although both steroidogenic tissues can synthesize ApoE and cholesterol de novo, about $80 \%$ of the cholesterol precursor for steroidogenesis is provided by serum lipoproteins. Therefore, ApoE gene is assumed to be the main regulator of cholesterol precursor concentration in both circulation and tissues $(32,33)$. Data on the association of the ApoE polymorphism and serum androgens in postmenopausal women are sparse and contradicting. According to Zofkova et al. (34), postmenopausal women bearing the $\mathrm{E} 4$ allele have increased serum androgens compared with women without the E4 allele. On the contrary, Barrett-Connor et al. (35) found no association of the E4 allele with serum testosterone. The same group, however, reported lower DHEAS levels in women bearing the $\mathrm{E} 4$ allele. These data, therefore, are preliminary and should be interpreted with caution, unless corroborated by larger studies.

An important limitation of this study is the relatively small sample size. As a consequence, the power of the study is limited and type II errors might have prevented the emergence of other weaker associations. However, the associations that have reached statistical significance in this context of limited sample size may be thought of as valid and reproducible in larger samples. Indeed, the magnitude of the herein documented associations was such that it overcame the critical $P$ value (type I error) of 0.05 despite the relatively small sample size. An additional limitation is the fact that we did not assess quantitatively insulin resistance.

Commenting further on the limitations of this study, it should be kept in mind that the correlation approach adopted herein does not substitute for biochemical research studies. This study is the first to provide evidence on the examined associations, but undoubtedly further biochemical studies are needed to elucidate the molecular mechanisms that underlie and explain the present findings. Nevertheless, to the best of our knowledge, this is the first study to indicate a link between genetic defects of Hcy metabolism and indices of androgenicity in healthy postmenopausal women.

In conclusion, the presence of Ala222Val polymorphism in the MTHFR gene is associated with increased central adiposity and serum androgen levels. The significance of this association with respect to the risk of CVD remains to be investigated.

\section{Acknowledgements}

We would like to thank the Hormonal and Biochemical Laboratory of the University of Athens in Aretaieio Hospital, who contacted the required biochemical, hormonal assays and genetic analysis, as well as all the colleagues who participated in this protocol.

\section{References}

1 Gaspard UJ, Gottal JM \& van den Brûle FA. Postmenopausal changes of lipid and glucose metabolism: a review of their main aspects. Maturitas 199521 171-178.

2 Rosano GM, Vitale C, Marazzi G \& Volterrani M. Menopause and cardiovascular disease: the evidence. Climacteric 200710 (Suppl 1) 19-24.

3 Zamboni M, Armellini F, Milani MP, De Marchi M, Todesco T, Robbi R, Bergamo-Andreis IA \& Bosello O. Body fat distribution in pre- and post-menopausal women: metabolic and anthropometric variables and their inter-relationships. International Journal of Obesity and Related Metabolic Disorders 199216 495-504.

4 Misra KB, Endemann SW \& Ayer M. Measures of obesity and metabolic syndrome in Indian Americans in northern California. Ethnicity \& Disease 200616 331-337.

5 Dalton M, Cameron AJ, Zimmet PZ, Shaw JE, Jolley D, Dunstan DW \& Welborn TA. Waist circumference, waist-hip ratio and body mass index and their correlation with cardiovascular disease risk factors in Australian adults. Journal of Internal Medicine 2003254 $555-563$

6 Wild RA. Obesity, lipids, cardiovascular risk, and androgen excess. American Journal of Medicine 199598 27S-32S.

7 Lee CC, Kasa-Vubu JZ \& Supiano MA. Androgenicity and obesity are independently associated with insulin sensitivity in postmenopausal women. Metabolism 200453 507-512.

8 Christodoulakos G, Lambrinoudaki I, Panoulis C, Sioulas V, Rizos D, Caramalis G, Botsis D \& Creatsas G. Serum androgen levels and insulin resistance in postmenopausal women: association with hormone therapy, tibolone and raloxifene. Maturitas $200550321-330$.

9 Weiss EJ, Bray PF, Tayback M, Schulman SP, Kickler TS, Becker LC, Weiss JL, Gerstenblith G \& Goldschmidt-Clermont PJ. A polymorphism of a platelet glycoprotein receptor as an inherited risk factor for coronary thrombosis. New England Journal of Medicine 1996334 1090-1094.

10 Cubrilo-Turek M, Stavljenić-Rukavina A, Sertić J, Zrinski R, Turek S, Grgac G \& Ljubojević N. Apolipoprotein E genotypes and metabolic risk factors for coronary heart disease in middleaged women. Collegium Antropologicum 199822 149-155. 
11 Sánchez-Marín B \& Grasa JM. Methylenetetrahydrofolate reductase (MTHFR) C677T polymorphism in ischemic vascular disease. Revista de Neurologia 200643 630-636.

12 Tybjaerg-Hansen A, Steffensen R, Meinertz H, Schnohr P \& Nordestgaard BG. Association of mutations in the apolipoprotein B gene with hypercholesterolemia and the risk of ischemic heart disease. New England Journal of Medicine 1998338 1577-1584.

13 Chen Q, Reis SE, Kammerer CM, McNamara DM, Holubkov R, Sharaf BL, Sopko G, Pauly DF, Merz CN \& Kamboh MI. WISE Study Group. Association between the severity of angiographic coronary artery disease and paraoxonase gene polymorphisms in the National Heart, Lung, and Blood Institute-sponsored Women's Ischemia Syndrome Evaluation (WISE) study. American Journal of Human Genetics $2003 \mathbf{7 2} 13-22$.

14 Martínez-Calatrava MJ, Martínez-Larrad MT, Zabena C, GonzálezSánchez JL, Fernández-Pérez C \& Serrano-Ríos M. The 4G/4G PAI1 genotype is associated with elevated plasma PAI-1 levels regardless of variables of the metabolic syndrome and smoking status. A population-based study in Spanish population. Diabetes, Obesity and Metabolism 20079 134-135.

15 Couture P, Otvos JD, Cupples LA, Wilson PWF, Schaefer EJ \& Ordovas JM. Association of the A-204C polymorphism in the cholesterol 7-hydroxylase gene with variations in plasma low density lipoprotein cholesterol levels in the Framingham Offspring Study. Journal of Lipid Research 199940 1883-1889.

16 Ordovas JM, Cupples LA, Corella D, Otvos JD, Osgood D, Martinez A, Lahoz C, Coltell O, Wilson PW \& Schaefer EJ. Association of cholesteryl ester transfer protein-TaqIB polymorphism with variations in lipoprotein subclasses and coronary heart disease risk: the Framingham study. Arteriosclerosis, Thrombosis, and Vascular Biology 200020 1323-1329.

17 Guzelmeric K, Alkan N, Pirimoglou M, Unal O \& Turan C. Chronic inflammation and elevated homocysteine levels are associated with increased body mass index in women with polycystic ovary. Gynecological Endocrinology 200723 505-510.

18 Huemer M, Vonblon K, Fodinger M, Krumpholz R, Hubmann M, Ulmer H \& Simma B. Total homocysteine, folate and cobalamine, and their relation to genetic polymorphisms, lifestyle and body mass index in healthy children and adolescents. Pediatric Research $200660764-769$.

19 Kawamoto R, Kohara K, Oka Y, Tomita H, Tabara Y \& Miki T. An association of 5,10-methylenetetrahydrofolate reductase (MTHFR) gene polymorphism and ischemic stroke. Journal of Stroke and Cerebrovascular Diseases 200514 67-74.

20 Couturaud F, Oger E, Abalain JH, Chenu E, Guias B, Floch HH, Mercier B, Mottier D \& Leroyer C. Methylenetetrahydrofolate

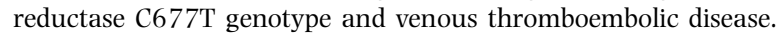
Respiration 200067 657-661.

21 Villa P, Suriano R, Costantini B, Macrì F, Ricciardi L, Campagna G \& Lanzone A. Hyperhomocysteinemia and cardiovascular risk in postmenopausal women: the role of folate supplementation. Clinical Chemistry and Laboratory Medicine 200745 130-135.

22 Wierzbicki AS. Homocysteine and cardiovascular disease: a review of the evidence. Diabetes and Vascular Disease Research 20074 143-149.
23 Carlsen SM, Kjotrod S, Vanky E \& Romundstad P. Homocysteine levels are unaffected by metformin treatment in both nonpregnant and pregnant women with polycystic ovary syndrome. Acta Obstetricia et Gynecologica Scandinavica 200786 145-150.

24 Giltay EJ, Hoogeven EK, Elbers JMH, Gooren LJG, Asscheman H \& Stehouwer CDA. Insulin resistance is associated with elevated plasma total homocysteine levels in healthy, non-obese subjects. Atherosclerosis $1998139197-198$.

25 McCarty MF. Insulin secretion as a potential determinant of homocysteine levels. Medical Hypotheses 200055 454-455.

26 Schachter M, Raziel A, Friedler S, Strassburger D, Bern O \& RonEI R. Insulin resistance in patients with polycystic ovary syndrome is associated with elevated homocysteine. Human Reproduction 200318 721-727.

27 Bjorck J, Hellgren M, Rastam L \& Lindblad U. Associations between serum insulin and homocysteine in a Swedish population - a potential link between the metabolic syndrome and hyperhomocysteinemia: the Skaraborg project. Metabolism: Clinical and Experimental 200655 1007-1013.

28 Dicker-Brown A, Fonseca VA, Fink LM \& Kern PA. The effect of glucose and insulin on the activity of methylene tetrahydrofolate reductase and cystathionine-beta-synthase: studies in hepatocytes. Atherosclerosis $2001 \mathbf{1 5 8} 297-301$.

29 Pinkney JH, Stehouwer CD, Coppack SW \& Yudkin JS. Endothelial dysfunction: cause of the insulin resistance syndrome. Diabetes 199746 S9-S13.

30 Christodoulakos GE, Lambrinoudaki IV, Rizos DA, Alexandrou A, Kountouris AV \& Creatsas GC. Endogenous sex steroids and circulating homocysteine in healthy Greek postmenopausal women. Hormones 20065 35-41.

31 Lambrinoudaki IV, Christodoulakos GE, Rizos DA, Economou E, Argeitis J, Vlachou S, Creatsa M, Kouskouni E \& Botsis D. Endogenous sex hormones and risk factors for atherosclerosis in healthy Greek postmenopausal women. European Journal of Endocrinology $2006154907-916$.

32 Heikkinen AM, Niskanen L, Ryynanen M, Komulainen MH, Tuppuraine MT, Parviainen M \& Saarikoski S. Is the response of serum lipids and lipoproteins to postmenopausal hormone replacement therapy modified by ApoE genotype? Arteriosclerosis, Thrombosis, and Vascular Biology $199919402-407$.

33 Singh CF \& Davignon J. Role of the apolipoprotein E polymorphism in determining normal plasma lipid and lipoprotein variation. American Journal of Human Genetics 198537 268-285.

34 Zofková I, Zajícková K, Hill M \& Horínek A. Apolipoprotein E gene determines serum testosterone and dehydroepiandrosterone levels in postmenopausal women. European Journal of Endocrinology 2002147 503-506.

35 Barrett-Connor E \& Von Muhlen D. The association of apolipoprotein E with sex hormones in a population-based sample of postmenopausal Caucasian women. European Journal of Endocrinology $2003 \mathbf{1 4 8} 487-488$.

Received 13 February 2008

Accepted 16 May 2008 